\title{
Association between Cervical Spondylosis and Migraine: A Nationwide Retrospective Cohort Study
}

\author{
Wang-Sheng Lin ${ }^{1,+}{ }^{\text {, Tung-Fu Huang }}{ }^{2,3,+}$, Tien-Yow Chuang ${ }^{1}$, Cheng-Li Lin ${ }^{4,5}$ and \\ Chia-Hung Kao ${ }^{6,7,8, * \text { (D) }}$ \\ 1 Department of Physical Medicine and Rehabilitation, Taipei Veterans General Hospital, Taipei 11217, \\ Taiwan; a8889bms47@gmail.com (W.-S.L.); tychuang@vghtpe.gov.tw (T.-Y.C.) \\ 2 Department of Surgery, Faculty of Medicine, National Yang-Ming University, Taipei 11221, Taiwan; \\ tungfuh@yahoo.com.tw \\ 3 Department of Orthopaedics \& Traumatology, Taipei Veterans General Hospital, Taipei 11217, Taiwan \\ 4 Management Office for Health Data, China Medical University Hospital, Taichung 404, Taiwan; \\ orangechengli@gmail.com \\ 5 College of Medicine, China Medical University, Taichung 404, Taiwan \\ 6 Graduate Institute of Clinical Medical Science and School of Medicine, College of Medicine, China Medical \\ University, No. 2, Yuh-Der Road, Taichung 404, Taiwan \\ 7 Department of Nuclear Medicine and PET Center, China Medical University Hospital, Taichung 404, Taiwan \\ 8 Department of Bioinformatics and Medical Engineering, Asia University, Taichung 413, Taiwan \\ * Correspondence: d10040@mail.cmuh.org.tw; Tel.: +886-4-2205-2121 (ext. 7412); Fax: +886-4-2233-6174 \\ + These authors contributed equally to this work.
}

Received: 6 February 2018; Accepted: 22 March 2018; Published: 25 March 2018

\begin{abstract}
Background: Few studies have investigated the longitudinal association between cervical spondylosis (CS) and migraine by using a nationwide population-based database. Methods: We conducted a retrospective cohort study from 2000 to 2011 identifying 27,930 cases of cervical spondylosis and 111,720 control subjects (those without cervical spondylosis) from a single database. The subjects were frequency-matched on the basis of sex, age, and diagnosis date. The non- cervical spondylosis cohort was four times the size of the cervical spondylosis cohort. To quantify the effects of cervical spondylosis on the risk of migraine, univariate and multivariate Cox proportional hazard regression analyses were used to calculate the hazard ratio (HR), and 95\% confidence interval (CI). Results: After a 10-year follow-up controlling for potential confounding factors, overall migraine incidence was higher in the cervical spondylosis cohort than in the non-cervical spondylosis cohort (5.16 and 2.09 per 1000 people per year, respectively; crude hazard ratio $=2.48,95 \%$ confidence interval $=2.28-2.69)$, with an adjusted hazard ratio of $2.03(95 \%$ confidence interval $=1.86-2.22)$ after accounting for sex, age, comorbidities, and medication. Individuals with myelopathy in the cervical spondylosis cohort had a 2.19 times (95\% confidence interval $=1.80-2.66)$ higher incidence of migraine when compared than did those in the non- cervical spondylosis cohort. Conclusions: Individuals with cervical spondylosis exhibited a higher risk of migraine than those without cervical spondylosis. The migraine incidence rate was even higher among individuals with cervical spondylotic myelopathy.
\end{abstract}

Keywords: cervical spondylosis; migraine; retrospective cohort study; population-based

\section{Introduction}

Migraine is the most prevalent and incapacitating neurovascular disorder worldwide, affecting approximately one billion people, exerting a considerable impact on quality of life, and representing a significant socioeconomic burden [1-3]. Speculated origins of pain are cortical 
neuronal hyperexcitability [4], modulatory dysfunction of brainstem and diencephalic systems [5], and peripheral activation [6], all of which lead to the release of vasoactive neuropeptides in the trigeminovascular system to process pain $[7,8]$.

Although many hypotheses regarding migraine triggers have been proposed, the significance of causal relationships between the triggers is obscured $[9,10]$. Among these triggers, cervical pathologies may initiate the sequence of events that results in migraine symptoms. The extensive functional convergence of upper cervical spinal cord from the descending fibers in the trigeminal nucleus caudalis, which terminates within the trigeminocervical nucleus, and the afferent fibers from the upper cervical roots, which communicate in this region, accounting for the bi-directional pathway of pain between the neck and head. This interaction refers the cervical pathologies to the head, which is the activity also proposed to cause cervicogenic headache [11]. Constantly noxious cervical afferent irritation via this pathway is a possible key element in causing migraines.

Neck pain and muscle tension are common migraine symptoms and both could be sequelae of neck injuries, according to the musculoskeletal anatomy [11,12]. Moreover, administering multiple injections in targeted head and neck regions is sometimes considered important for the management of migraines, cervicogenic headaches, and myofascial referred pain [11,13-16], indicating that headache and neck pain may share some common pathways.

Although a previous report indicated that cervical spondylosis (CS) accounts for $15.9 \%$ of migraineurs [17], until now epidemiological evidence of a link between CS and the risk of migraine is minimal. Therefore, we conducted this nationwide retrospective cohort study to investigate the longitudinal causal relationship between CS and migraines and CS severity in relation to the risk of developing a migraine.

\section{Methods}

\subsection{Data Source}

The data used in this retrospective study was retrieved from the Longitudinal Health Insurance Database 2000 (LHID2000) of Taiwan, a subdataset of the National Health Insurance Research Database (NHIRD) that comprises 1,000,000 randomly selected people from the NHIRD. The NHIRD of Taiwan contains the detailed health care data of more than $99 \%$ of the Taiwanese population (more than 23.74 million residents) [18]. The LHID2000 has been successfully applied in numerous studies [19,20]. The diagnostic coding in our study was according to the Ninth Revision ICD-9-CM (the International Classification of Diseases-Clinical Modification). Our study was approved by the IRB (Institutional Review Board) in China Medical University (CMUH104-REC2-115-CR2). Because the patients' personal information is anonymous without identification numbers, therefore the informed consent was not required. The dataset is belonging to the Taiwan Ministry of Health and Welfare (MOHW)

\subsection{Sampled Participants}

We selected individuals aged $\geq 18$ years diagnosed with CS without (ICD-9-CM code 721.0) or with (ICD-9-CM code 721.1) myelopathy from 2000 to 2010 as the CS cohort. The diagnosis time of the CS cohort was defined to be the index date. We randomly selected the non-CS cohort (the control subjects) at a 4:1 ratio from the database to match with the CS cohort. Participants in both of the cohorts with previous migraine diagnoses (ICD-9-CM code 346) were excluded. The medical fraud by overbilling for health care or cheating charges based on incorrect diagnoses were avoided carefully, and the NHI Bureau in Taiwan monitored the disease coding strictly. As aforementioned, highly prevention from the coding errors, misdiagnosis, or improper therapy supported the reliability of NHIRD data to explore the risk of migraine in CS patients. Moreover, the diagnosis of migraine based on the International Classification of Headache Disorders (ICHD-3) criteria (the 3rd edition) was only made by the professional neurologists in Taiwan, which increased the confidence of the accuracy [21]. Regarding the diagnosis of CS with myelopathy, it required a careful correlation between findings 
from the nature history and clinical examination, supported by radiological evidence showing spinal cord compression. Furthermore, the NHI regulated the coding and audited insurance reimbursement claims routinely.

\subsection{Outcome and Comorbidities}

We followed the participants in the CS and non-CS cohorts until migraine diagnoses were made or the participants were censored because of withdrawal from the National Health Insurance (NHI) program or until 31 December 2011. Pre-existing comorbidities for each individual included hypertension (ICD-9-CM codes 401-405), hyperlipidemia (ICD-9-CM code 272), depression (ICD-9-CM codes 296.2-296.3, 300.4, 311), coronary artery disease (ICD-9-CM codes 410-414), anxiety (ICD-9-CM codes 300.0, 300.2, 300.3, 308.3, 309.81), sleep disorders (ICD-9-CM codes 307, 780.5), irritable bowel syndrome (ICD-9-CM code 564.1), diabetes (ICD-9-CM code 250), and fibromyalgia (ICD-9-CM code 729.1).

\subsection{Statistical Analysis}

We used Chi-square tests and Student's $t$ tests to compare sex, age, and comorbidities between the CS and non-CS cohorts. Cumulative incidences of migraines in both of the cohorts were compared using the Kaplan-Meier method and variations between the two cohorts were compared using a log-rank test. We calculated the incidence rate of migraines based on various risk factors and stratified the results based on sex, age, and comorbidities. We used Cox proportional hazard regression models to measure the hazard ratios (HRs) and 95\% confidence intervals (CIs) to assess the risk of migraine after adjustments for age, sex, and the related comorbidities. In addition, the relative risk of migraine development stratified based on sex, age, and comorbidities in both of the cohorts was analyzed for comparison. These above statistical measurements were analyzed based on SAS (version 9.4 for Windows, SAS Institute, Cary, NC, USA).

\section{Results}

The CS and non-CS cohorts comprised 27,930 and 111,720 cases, respectively. Among all of the participants, $56.9 \%$ were women and $73.7 \%$ were aged under 64 years (Table 1 ). The mean ages of both cohorts were $44.8 \pm 16.6$ (CS) and $44.5 \pm 16.8$ years (non-CS). The CS cohort exhibited higher prevalence of all baseline comorbidities. During the mean follow-up of 6.13 (standard deviation $(S D)=3.19)$ years for the CS cohort and $6.07(S D=3.20)$ years for the non-CS cohort, the cumulative incidence of migraines was higher among individuals with CS than those without (log-rank test $p<0.001$ ) (Figure 1).

The migraine incidence rates were 5.16 and 2.09 per 1000 people per year in the CS and non-CS cohorts, respectively (Table 2). The risk of migraine was higher in the CS cohort than in the non-CS cohort (adjusted HR $(\mathrm{aHR})=2.03,95 \% \mathrm{CI}=1.86-2.22)$. When compared with individuals that are aged $\geq 65$ years, individuals aged $20-49$ years $(\mathrm{aHR}=1.81,95 \% \mathrm{CI}=1.58-2.06)$ and $50-64$ years $(\mathrm{aHR}=1.40$, $95 \% \mathrm{CI}=1.24-1.58$ ) had a higher risk of developing migraine. The aHR values revealed that the risk of developing migraine was 1.92 times higher among women than men. The multivariate Cox model revealed that the risk of migraine was higher among individuals with the comorbidities of hypertension, hyperlipidemia, depression, coronary artery disease, anxiety, sleep disorders, irritable bowel syndrome, diabetes, and fibromyalgia. 


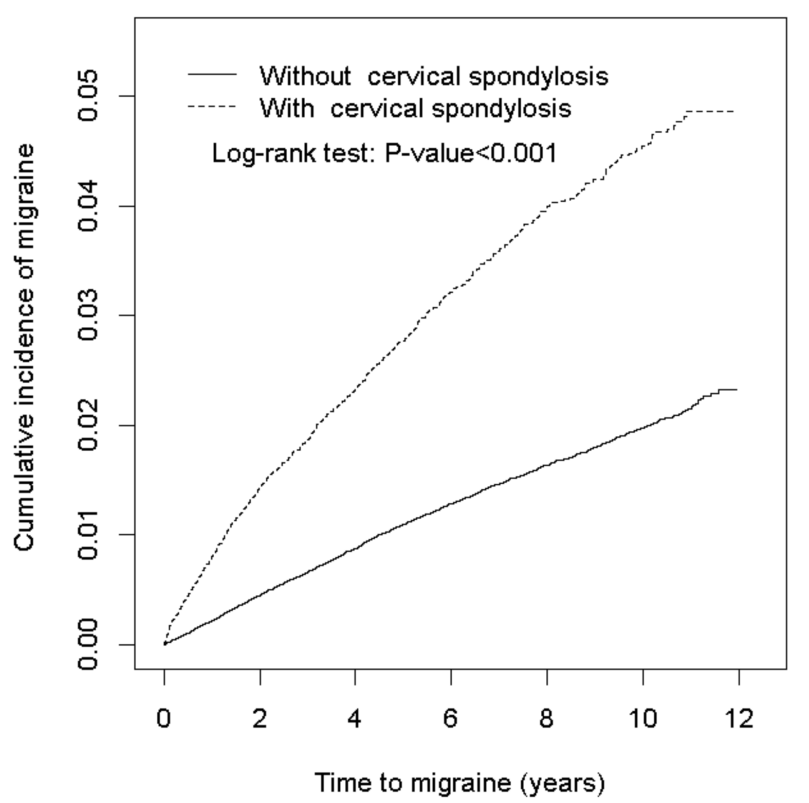

Figure 1. Cummulative incidence of migraine in individuals with and without cervical spondylosis (CS).

Table 1. Comparisons of demographic characteristics and comorbidities in individuals with and without CS.

\begin{tabular}{|c|c|c|c|}
\hline \multirow[b]{2}{*}{ Variable } & \multicolumn{3}{|c|}{ Cervical Spondylosis } \\
\hline & $\begin{array}{c}\text { No } \\
(N=111,720)\end{array}$ & $\begin{array}{c}\text { Yes } \\
(N=27,930)\end{array}$ & $\begin{array}{l}\text { Standard Mean } \\
\text { Difference }\end{array}$ \\
\hline Sex & & & 0.99 \\
\hline Women & $63,592(56.9)$ & $15,898(56.9)$ & \\
\hline Men & $48,128(43.1)$ & $12,032(43.1)$ & \\
\hline Age stratified & & & 0.99 \\
\hline$\leq 49$ & $40,452(36.2)$ & $10,113(36.2)$ & \\
\hline $50-64$ & $41,880(37.5)$ & $10,470(37.5)$ & \\
\hline $65+$ & $29,388(26.3)$ & $7347(26.3)$ & \\
\hline $\begin{array}{l}\text { Age, mean } \pm \mathrm{SD}^{\mathrm{a}} \\
\text { Comorbidity }\end{array}$ & $55.1(14.0)$ & $55.6(13.6)$ & $<0.001$ \\
\hline Hypertension & $36,886(33.0)$ & $11,658(41.7)$ & $<0.001$ \\
\hline Hyperlipidemia & $22,730(20.4)$ & $8887(31.8)$ & $<0.001$ \\
\hline Depression & $4498(4.03)$ & $2252(8.06)$ & $<0.001$ \\
\hline Coronary artery disease & $17,160(15.4)$ & 6941(24.9) & $<0.001$ \\
\hline Anxiety & $10,300(9.22)$ & $5607(20.1)$ & $<0.001$ \\
\hline Sleep disorder & $20,851(18.7)$ & $9450(33.8)$ & $<0.001$ \\
\hline Irritable bowel syndrome & $4969(4.45)$ & $2487(8.90)$ & $<0.001$ \\
\hline Diabetes & $10,876(9.74)$ & 3182(11.4) & $<0.001$ \\
\hline Fibromyalgia & $4599(4.12)$ & 2984(10.7) & $<0.001$ \\
\hline
\end{tabular}

Chi-square test; ${ }^{a} t$ test; CS cohort follow-up time mean = 6.13 (3.19); Non-CS cohort follow-up time mean = 6.07 (3.20).

The incidence and risk of migraine in both cohorts were compared based on the variables of sex, age, and comorbidities (Table 3). For all of the variables, the risk of migraine remained higher in the CS cohort than those in the non-CS cohort.

Table 4 shows the incidence and aHR values of migraine associated with different various forms of CS. The participants with myelopathy in the CS cohort exhibited a 2.19 times higher risk of migraine (95\% CI $=1.80-2.66)$ than those in the non-CS cohort, whereas those without myelopathy exhibited a 2.01 times higher risk in the CS cohort $(95 \% \mathrm{CI}=1.83-2.20)$. As noted, the age intervals used to 
stratify were under 49 years, from 50 to 64 years, above 65 years. The numbers for each age cohort are $1293(35.5 \%), 1302(35.7 \%)$, and 1048(28.8\%), respectively.

Table 2. Migraine incidences and risk factors.

\begin{tabular}{|c|c|c|c|c|c|}
\hline Variable & Event & PY & Rate \# & Crude HR (95\% CI) & Adjusted HR \& $(95 \%$ CI $)$ \\
\hline \multicolumn{6}{|c|}{ Cervical spondylosis } \\
\hline No & 1414 & 677,913 & 2.09 & 1.00 & 1.00 \\
\hline Yes & 883 & 171,179 & 5.16 & $2.48(2.28,2.69)^{* * *}$ & $2.03(1.86,2.22)^{* * *}$ \\
\hline \multicolumn{6}{|c|}{ Age group, year } \\
\hline $20-49$ & 997 & 330,050 & 3.02 & $1.46(1.31,1.64)^{* * *}$ & $1.81(1.58,2.06)^{* * *}$ \\
\hline $50-64$ & 874 & 317,220 & 2.76 & $1.32(1.18,1.48)^{* * * *}$ & $1.40(1.24,1.58)^{* * *}$ \\
\hline$\geq 65$ & 426 & 201,822 & 2.11 & 1.00 & 1.00 \\
\hline \multicolumn{6}{|l|}{ Sex } \\
\hline Female & 1719 & 494,959 & 3.47 & $2.14(1.95,2.35)^{* * *}$ & $1.92(1.74,2.11)^{* * *}$ \\
\hline Male & 578 & 354,133 & 1.63 & 1.00 & 1.00 \\
\hline \multicolumn{6}{|c|}{ Comorbidity } \\
\hline \multicolumn{6}{|c|}{ Hypertension } \\
\hline No & 1465 & 570,275 & 2.57 & 1.00 & 1.00 \\
\hline Yes & 832 & 278,816 & 2.98 & $1.15(1.06,1.25)^{* *}$ & $1.06(0.95,1.18)$ \\
\hline \multicolumn{6}{|c|}{ Hyperlipidemia } \\
\hline No & 1698 & 668,229 & 2.54 & 1.00 & 1.00 \\
\hline Yes & 599 & 180,862 & 3.31 & $1.29(1.17,1.41)^{* * *}$ & $1.01(0.91,1.12)$ \\
\hline \multicolumn{6}{|c|}{ Depression } \\
\hline No & 2090 & 813,829 & 2.57 & 1.00 & 1.00 \\
\hline Yes & 207 & 35,263 & 5.87 & $2.24(1.94,2.58)^{* * *}$ & $1.13(0.97,1.32)$ \\
\hline \multicolumn{6}{|c|}{ Coronary artery disease } \\
\hline No & 1800 & 711,569 & 2.53 & 1.00 & 1.00 \\
\hline Yes & 497 & 137,523 & 3.61 & $1.42(1.28,1.56)^{* * *}$ & $1.20(1.07,1.35)^{* *}$ \\
\hline \multicolumn{6}{|l|}{ Anxiety } \\
\hline No & 1785 & 764,303 & 2.34 & 1.00 & 1.00 \\
\hline Yes & 512 & 84,789 & 6.04 & $2.53(2.30,2.80)^{* * *}$ & $1.48(1.32,1.66)^{* * *}$ \\
\hline \multicolumn{6}{|c|}{ Sleep disorder } \\
\hline No & 1444 & 690,750 & 2.09 & 1.00 & 1.00 \\
\hline Yes & 853 & 158,342 & 5.39 & $2.52(2.31,2.74)^{* * *}$ & $1.81(1.64,1.99)^{* * *}$ \\
\hline \multicolumn{6}{|c|}{ Irritable bowel syndrome } \\
\hline No & 2105 & 809,522 & 2.60 & 1.00 & 1.00 \\
\hline Yes & 192 & 39,569 & 4.85 & $1.83(1.57,2.12)^{* * *}$ & $1.24(1.06,1.44)^{* *}$ \\
\hline \multicolumn{6}{|l|}{ Diabetes } \\
\hline No & 2112 & 775,714 & 2.72 & 1.00 & 1.00 \\
\hline Yes & 185 & 73,378 & 2.52 & $0.91(0.78,1.05)$ & - \\
\hline \multicolumn{6}{|c|}{ Fibromyalgia } \\
\hline No & 2127 & 808,699 & 2.63 & 1.00 & 1.00 \\
\hline Yes & 170 & 4093 & 4.21 & $1.57(1.34,1.83)^{* * *}$ & $1.08(0.92,1.27)$ \\
\hline
\end{tabular}

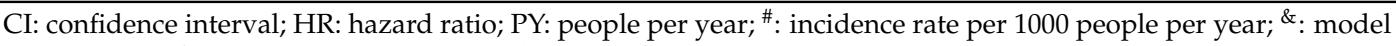
was adjusted for age, sex, and the comorbidities of hypertension, hyperlipidemia, depression, coronary artery disease, anxiety, sleep disorders, irritable bowel syndrome, and fibromyalgia by using Cox proportional hazards regression; ${ }^{* *} p<0.01 ;{ }^{* * *} p<0.001$. 
Table 3. Comparison of incidence rate of migraine hazard ratios (HR) between individuals with and without CS based on demographic characteristics and comorbidities.

\begin{tabular}{|c|c|c|c|c|c|c|c|c|}
\hline \multirow{3}{*}{ Variable } & \multicolumn{8}{|c|}{ Cervical spondylosis } \\
\hline & \multicolumn{3}{|c|}{ No } & \multicolumn{3}{|c|}{ Yes } & \multirow{2}{*}{$\begin{array}{c}\text { Crude HR }(95 \% \\
\text { CI) }\end{array}$} & \multirow{2}{*}{$\begin{array}{l}\text { Adjusted HR \& } \\
(95 \% \mathrm{CI})\end{array}$} \\
\hline & Event & PY & Rate $^{\#}$ & Event & PY & Rate $^{\#}$ & & \\
\hline \multicolumn{9}{|l|}{ Sex } \\
\hline Women & 1082 & 395,676 & 2.73 & 637 & 99,282 & 6.42 & $2.35(2.13,2.59)^{* * *}$ & $1.93(1.74,2.14)^{* * *}$ \\
\hline Men & 332 & 282,237 & 1.18 & 246 & 71,896 & 3.42 & $2.91(2.47,3.44)^{* * *}$ & $2.32(1.95,2.76)^{* * *}$ \\
\hline \multicolumn{9}{|l|}{ Stratify age } \\
\hline$\leq 49$ & 620 & 264,087 & 2.35 & 377 & 65,963 & 5.72 & $2.44(2.14,2.77) * * *$ & $1.94(1.70,2.23) * * *$ \\
\hline $50-64$ & 532 & 253,619 & 2.10 & 342 & 63,600 & 5.38 & $2.56(2.24,2.94)^{* * *}$ & $2.05(1.78,2.36)^{* * *}$ \\
\hline $65+$ & 377 & 160,207 & 1.64 & 164 & 41,615 & 3.94 & $2.42(1.99,2.94)^{* * *}$ & $2.08(1.70,2.55)^{* * *}$ \\
\hline \multicolumn{9}{|c|}{ Comorbidity $\ddagger$} \\
\hline No & 520 & 342,246 & 1.52 & 180 & 49,454 & 3.64 & $2.40(2.02,2.84) * * *$ & $2.36(1.99,2.80)^{* * *}$ \\
\hline Yes & 894 & 335,667 & 2.66 & 703 & 121,725 & 5.78 & $2.19(1.98,2.41)^{* * *}$ & $2.10(1.91,2.32) * * *$ \\
\hline
\end{tabular}

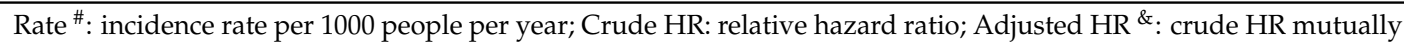
adjusted for age, sex, and the comorbidities of hypertension, hyperlipidemia, depression, coronary artery disease, anxiety, sleep disorders, irritable bowel syndrome, and fibromyalgia by using Cox proportional hazards regression; Comorbidity $\ddagger$ : individuals with any one of the comorbidities of hypertension, hyperlipidemia, depression, coronary artery disease, anxiety, sleep disorders, irritable bowel syndrome, diabetes, and fibromyalgia were classified in the comorbidity group; ${ }^{* * *} p<0.001$.

Table 4. Migraine incidences and HRs among individuals with various types of CS and those without CS.

\begin{tabular}{|c|c|c|c|c|c|c|}
\hline Variable & $\mathbf{N}$ & Events & PYs & Rate \# & Crude HR $(95 \%$ CI) & $\begin{array}{c}\text { Adjusted HR \& } \\
95 \% \mathrm{CI})\end{array}$ \\
\hline $\begin{array}{l}\text { Without cervical spondylosis } \\
\text { Type of Cervical spondylosis }\end{array}$ & 111,720 & 1414 & 677,913 & 2.09 & 1.00 & 1.00 \\
\hline $\begin{array}{l}\text { Cervical spondylosis without } \\
\text { myelopathy }\end{array}$ & 24,287 & 771 & 150,298 & 5.13 & $2.47(2.26,2.69)^{* * *}$ & $2.01(1.83,2.20)^{* * *}$ \\
\hline $\begin{array}{l}\text { Cervical spondylosis with } \\
\text { myelopathy }\end{array}$ & 3643 & 112 & 20,880 & 5.36 & $2.55(2.10,3.09)^{* * *}$ & $2.19(1.80,2.66)^{* * *}$ \\
\hline
\end{tabular}

Rate\#: incidence rate per 1000 people per year; Crude HR: relative hazard ratio; Adjusted HR \&: crude HR mutually adjusted for age, sex, and the comorbidities of hypertension, hyperlipidemia, depression, coronary artery disease, anxiety, sleep disorders, irritable bowel syndrome, and fibromyalgia by using Cox proportional hazards regression; *** $p<0.001$

\section{Discussion}

This study is the first to use a population-based database to demonstrate the long-term risk of migraine in individuals with CS. The primary findings support our hypothesis that individuals with CS are at a higher risk of developing migraine than those without CS. The cumulative migraine frequency at the conclusion of the follow-up period was higher in the CS cohort than in the non-CS group. The migraine rates among 1000 people per year were 5.16 and 2.09 in the CS and non-CS cohorts, respectively. Moreover, the CS cohort exhibited a 2.03 times higher risk of migraine $(95 \% \mathrm{CI}=$ 1.86-2.22) than the non-CS cohort. Furthermore, in the CS cohort, the participants with myelopathy were at a higher risk of developing a migraine than those without myelopathy.

Cervical musculoskeletal abnormalities and headache disorders were a bi-directional comorbidity, with nearly two-thirds of migraineurs coexisting with neck pain or stiffness, and one-fifth of patients with cervicogenic headache in pain clinics [22,23]. Previous studies have disclosed that almost $90 \%$ patients with headache accepted anterior cervical operation for the treatment of symptoms with cervical myelopathy or radiculopathy $[24,25]$. Furthermore, the authors observed that patients with headache disorders presented the myofascial trigger points, clear-cut areas of muscle tenderness, and posture changes, when compared with non-headache control $[22,26]$. Thus, our results corroborate those of previous studies on the linking between cervical spine disorder and migraine, emphasizing the importance of assessment for migraine at first and follow-up period in CS patients due to the increasing risk for the development of migraine. 
Regarding the effects of age and gender on migraine development, our results correlate with those of previous studies [3,27], which have demonstrated that young and middle-aged women with CS develop migraine more easily than do other individuals. Adjustments for the factors of sex, age, hypertension, hyperlipidemia, depression, anxiety, sleep disorders, coronary artery disease, irritable bowel syndrome, and fibromyalgia achieved statistical significance. Only the result of diabetes was insignificant. Although CS is an age-related disorder affecting the discs and vertebrae of the cervical spine, notably, the HR of the migraine occurrence did not increase with age [28]. First, we assumed that the inflammatory effects of the nucleus rather than the degenerative factor in female adults that are aged under 50 years might play a role in migraine development [28]. Persistent peripheral nociceptive impulses may induce neuroplastic changes in the spinal cord and brain, causing central sensitization and pain. Therefore, the combination of tonic nociceptive input and central disinhibition may play a role in migraine development [29]. In vivo, a slow progressive cord irritation resulted in complement-mediated response, contributing to the synapse destruction, neuronal and oligodendrocyte death [30,31]. Moreover, recent imaging advances also demonstrated that patients with more severe CS correlated with higher inflammation volumes [32]. The findings indicated that inflammatory cascade might serve as the potential molecular mechanisms underlying the pathogenesis of cervical spondylotic myelopathy, leading to migraine attack. Second, increased inflammation in the cervical spine due to the proinflammatory molecules release into the bloodstream upregulated the hypothalamic-pituitary-adrenal axis, causing the hypothalamic dysfunction [33]. This process intensified the sensitivity to pain in the brain, which may lead to predisposition to migraine.

Understanding of the precise mechanisms of the relationship between CS and migraine risk remains limited. Cervical vertebral degenerative processes can compromise the capsular ligaments of facet joints, thereby contributing to the hypermobility of upper cervical vertebrae [34]. Such cervical instability causes the dysregulation of the vertebrobasilar arteries, which leads to migraines [35,36]. Watson and Drummond assessed the effects of sustained pressure on the atlanto-occipital segments and C2-3 zygapophyseal joints to relieve migraines [37]. In addition, several studies have reported that myofascial trigger points could reproduce migraine symptoms [38,39], Moreover, an increasing amount of evidence shows that dyscoordination between the dorsal horns of the upper cervical spinal cord and trigeminal nucleus caudalis may induce cervicogenic headaches. The prolonged irritated inputs implicate in the pain processing through trigeminovascular system, which can provoke and worsen the symptoms of migraine $[40,41]$.

Regarding CS severity, our results revealed in the CS cohort, the participants with myelopathy may be at a greater risk of developing migraine than those without myelopathy. Revanappa et al. demonstrated that more than $50 \%$ of individuals with cervical spondylotic myelopathy also had concomitant autonomic dysfunction [42], where sympathetic postganglionic fibers exit through cervical posterior longitudinal ligaments [43]. In these individuals, once the ligaments had been compressed, abnormal activities in the middle cervical ganglia occurred [44], which could partially explain the progression of autonomic dysfunction due to cervical spondylotic myelopathy. Such structural and functional alternations in the cervical spinal cord may upregulate the associated nociceptive expressions, which could contribute to migraine development.

Our study has several clinical implications in public health. Firstly, clinicians should assess CS patients for migraine from beginning to follow-up because of the risk for developing the disorder. Secondly, as cervical spondylosis increased the risk of migraine, particularly in young to middle-aged women with CS and comorbidities, physicians should do the headache survey carefully for those susceptible patients. Thirdly, our results demonstrated that migraine incidence rate was even higher among individuals with cervical spondylotic myelopathy, which suggested that additional research is needed to evaluate the influence of CS severity.

Although this study has the advantage of feasibility and generalizability because of the large sample size and low dropout rate, it had several flaws. Firstly, the NHIRD has limitations, particularly in relation to biographical information, such as clinical features, imaging findings, laboratory studies, 
personal lifestyle, and medication, all of which are irretrievable. Secondly, the diagnostic accuracy of CS and migraine were totally dependent based on ICD-9-CM codes. In theory, the diagnosis of CS with or without myelopathy should be on the basis of the appropriate imaging evidence together with physical examinations and history taking. Generally, neurologists in Taiwan developed a headache diary as well as a structured intake form to do the headache survey (clinical headache pattern, psychological comorbidities, medication use and treatment response, functional disability, and quality of life) [45], the diagnosis of migraine based on the International Classification of Headache Disorders (ICHD-3) criteria (the 3rd edition). However, no one could confirm whether patients with the coding were accurately diagnosed due to the inherent weakness for all of the studies based on databank. Nonetheless, our results remain reliable because the NHI administration ministry randomly samples the medical charts routinely, verifying the coding in NHIRD dataset from every contracted medical institution. Thirdly, our database was derived from the NHI program in Taiwan, which predominantly enrolls Taiwanese citizens. The genetic factor of our participants would have been minimized in our study. However, there was no corresponding ICD-9-CM code for any particular type of migraine. Relationship between CS and any particular type of migraine (with and without aura) could not be substantiated, the more definite coding is required to strengthen the association between CS and migraine subtype.

\section{Conclusions}

CS increases the risk of migraine, especially in individuals with cervical spondylotic myelopathy. We showed that young to middle-aged women with CS and comorbidities were at the highest risk of migraine. Although the precise underlying mechanisms of this longitudinal association remain unknown, our results indicated that these two entities are closely related. However, in daily clinical practice, this truth will not come to light, multimodal management of migraine is highly required by the clinical practitioners.

Acknowledgments: This work was supported by grants from the Ministry of Health and Welfare, Taiwan (MOHW107-TDU-B-212-123004), China Medical University Hospital; Academia Sinica Stroke Biosignature Project (BM10701010021); MOST Clinical Trial Consortium for Stroke (MOST 106-2321-B-039-005-); Tseng-Lien Lin Foundation, Taichung, Taiwan; and Katsuzo and Kiyo Aoshima Memorial Funds, Japan. The funders had no role in study design, data collection and analysis, decision to publish, or preparation of the manuscript. No additional external funding received for this study.

Author Contributions: Conceptualization: W.-S.L., C.-H.K.; Data curation: W.-S.L., T.-F.H., T.-Y.C., C.-L.L., C.-H.K.; Formal analysis: W.-S.L., T.-F.H., T.-Y.C., C.-L.L., C.-H.K.; Funding acquisition: C.-H.K.; Investigation: W.-S.L., C.-H.K.; Methodology: C.-L.L., C.-H.K.; Project administration: C.-H.K.; Resources: W.-S.L., C.-H.K.; Software: C.-L.L., C.-H.K.; Supervision: C.-H.K.; Validation: W.-S.L., T.-F.H., T.-Y.C., C.-L.L., C.-H.K.; Visualization: W.-S.L., T.-F.H., T.-Y.C., C.-L.L., C.-H.K.; Writing (original draft preparation): W.-S.L., T.-F.H., T.-Y.C., C.-L.L., C.-H.K.; Writing (review and editing): W.-S.L., T.-F.H., T.-Y.C., C.-L.L., C.-H.K.

Conflicts of Interest: The authors declare no conflict of interest.

\section{Abbreviations}

CS

HR hazard ratio

cervical spondylosis

CI confidence interval

NHIRD National Health Insurance Research Database

LHID2000 Longitudinal Health Insurance Database 2000

ICD-9-CM International Classification of Diseases, Ninth Revision, Clinical Modification

\section{References}

1. Vos, T.; Abajobir, A.A.; Abbafati, C.; Abate, K.H.; Abbas, K.M.; Abd-Allah, F.; Abdulkader, R.S.; Abdulle, A.M.; Abebo, T.A.; Abera, S.F.; et al. Global, regional, and national incidence, prevalence, and years lived with disability for 328 diseases and injuries for 195 countries, 1990-2016: A systematic analysis for the Global Burden of Disease Study 2016. Lancet 2017, 390, 1211-1259. [CrossRef] 
2. Steiner, T.J.; Stovner, L.J.; Vos, T.; Jensen, R.; Katsarava, Z. Migraine is first cause of disability in under 50s: Will health politicians now take notice? J. Headache Pain 2018, 19, 17. [CrossRef] [PubMed]

3. Bloudek, L.M.; Stokes, M.; Buse, D.C.; Wilcox, T.K.; Lipton, R.B.; Goadsby, P.J.; Varon, S.F.; Blumenfeld, A.M.; Katsarava, Z.; Pascual, J.; et al. Cost of healthcare for patients with migraine in five European countries: Results from the International Burden of Migraine Study (IBMS). J. Headache Pain 2012, 13, 361-378. [CrossRef] [PubMed]

4. Costa, C.; Tozzi, A.; Rainero, I.; Cupini, L.M.; Calabresi, P.; Ayata, C.; Sarchielli, P. Cortical spreading depression as a target for anti-migraine agents. J. Headache Pain 2013, 14, 62. [CrossRef] [PubMed]

5. Akerman, S.; Holland, P.R.; Goadsby, P.J. Diencephalic and brainstem mechanisms in migraine. Nat. Rev. Neurosci. 2011, 12, 570-584. [CrossRef] [PubMed]

6. Olesen, J.; Burstein, R.; Ashina, M.; Tfelt-Hansen, P. Origin of pain in migraine: Evidence for peripheral sensitisation. Lancet Neurol. 2009, 8, 679-690. [CrossRef]

7. Gasparini, C.F.; Smith, R.A.; Griffiths, L.R. Genetic and biochemical changes of the serotonergic system in migraine pathobiology. J. Headache Pain 2017, 18, 20. [CrossRef] [PubMed]

8. Tajti, J.; Vecsei, L. The mechanism of peripheral and central sensitization in migraine. A literature review. Neuropsychopharmacol. Hung. 2009, 11, 15-21. [PubMed]

9. Martin, P.R. Behavioral Management of Migraine Headache Triggers: Learning to Cope with Triggers. Curr. Pain Headache Rep. 2010, 14, 221-227. [PubMed]

10. Levy, D.; Strassman, A.M.; Burstein, R. A Critical View on the Role of Migraine Triggers in the Genesis of Migraine Pain. Headache 2009, 49, 953-957. [CrossRef] [PubMed]

11. Biondi, D.M. Cervicogenic headache: A review of diagnostic and treatment strategies. J. Am. Osteopath. Assoc. 2005, 105, 16S-22S. [PubMed]

12. Kaniecki, R.G. Migraine and tension-type headache-An assessment of challenges in diagnosis. Neurology 2002, 58, S15-S20. [PubMed]

13. Escher, C.M.; Paracka, L.; Dressler, D.; Kollewe, K. Botulinum toxin in the management of chronic migraine: Clinical evidence and experience. Ther. Adv. Neurol. Disord. 2017, 10, 127-135. [CrossRef] [PubMed]

14. Szok, D.; Csati, A.; Vecsei, L.; Tajti, J. Treatment of Chronic Migraine with OnabotulinumtoxinA: Mode of Action, Efficacy and Safety. Toxins 2015, 7, 2659-2673. [CrossRef] [PubMed]

15. Robbins, M.S.; Kuruvilla, D.; Blumenfeld, A.; Charleston, L.; Sorrell, M.; Robertson, C.E.; Grosberg, B.M.; Bender, S.D.; Napchan, U.; Ashkenazi, A. Trigger point injections for headache disorders: Expert consensus methodology and narrative review. Headache 2014, 54, 1441-1459. [CrossRef] [PubMed]

16. Fernandez-de-las-Penas, C.; Cuadrado, M.L. Therapeutic options for cervicogenic headache. Expert Rev. Neurother. 2014, 14, 39-49. [PubMed]

17. Martinovic, Z.; Buder, N.; Velickovic, R.; Milovanovic, M. Comorbidity of migraine and somatic diseases. Med. Pregl. 2005, 58, 342-346. [PubMed]

18. Database NHIR. Taiwan. 2016. Available online: http://nhird.nhri.org.tw/en/index.html (accessed on 28 June 2016).

19. Hu, W.S.; Lin, C.L. CHA2DS2-VASc score for ischaemic stroke risk stratification in patients with chronic obstructive pulmonary disease with and without atrial fibrillation: A nationwide cohort study. EP Eur. 2017. [CrossRef] [PubMed]

20. Lee, C.W.; Lin, C.L.; Lin, P.Y.; Thielke, S.; Su, K.P.; Kao, C.H. Antidepressants and risk of dementia in migraine patients: A population-based case-control study. Prog. Neuropsychopharmacol. Biol. Psychiatry 2017, 77, 83-89. [PubMed]

21. Wang, S.J.; Fuh, J.L.; Huang, S.Y.; Yang, S.S.; Wu, Z.A.; Hsu, C.H.; Wang, C.H.; Yu, H.Y.; Wang, P.J.; Taiwan MAP Study Group. Diagnosis and development of screening items for migraine in neurological practice in Taiwan. J. Formos. Med. Assoc. 2008, 107, 485-494. [PubMed]

22. Blau, J.N.; MacGregor, E.A. Migraine and the neck. Headache 1994, 34, 88-90. [CrossRef] [PubMed]

23. Haldeman, S.; Dagenais, S. Cervicogenic headaches: A critical review. Spine J. 2001, 1, 31-46. [CrossRef]

24. Schrot, R.J.; Mathew, J.S.; Li, Y.; Beckett, L.; Bae, H.W.; Kim, K.D. Headache relief after anterior cervical discectomy: Post hoc analysis of a randomized investigational device exemption trial. J. Neurosurg. Spine 2014, 21, 217-222. [CrossRef] [PubMed] 
25. Riina, J.; Anderson, P.A.; Holly, L.T.; Flint, K.; Davis, K.E.; Riew, K.D. The Effect of an Anterior Cervical Operation for Cervical Radiculopathy or Myelopathy on Associated Headaches. J. Bone Joint Surg. Am. 2009, 91A, 1919-1923. [CrossRef] [PubMed]

26. Marcus, D.A.; Scharff, L.; Mercer, S.; Turk, D.C. Musculoskeletal abnormalities in chronic headache: A controlled comparison of headache diagnostic groups. Headache 1999, 39, 21-27. [CrossRef] [PubMed]

27. Vetvik, K.G.; MacGregor, E.A. Sex differences in the epidemiology, clinical features, and CrossMark pathophysiology of migraine. Lancet Neurol. 2017, 16, 76-87. [CrossRef]

28. Wang, C.; Tian, F.; Zhou, Y.; He, W.; Cai, Z. The incidence of cervical spondylosis decreases with aging in the elderly, and increases with aging in the young and adult population: A hospital-based clinical analysis. Clin. Interv. Aging 2016, 11, 47-53. [PubMed]

29. Woolf, C.J. Central sensitization: Implications for the diagnosis and treatment of pain. Pain 2011, 152, S2-S15. [CrossRef] [PubMed]

30. Takano, M.; Kawabata, S.; Komaki, Y.; Shibata, S.; Hikishima, K.; Toyama, Y.; Okano, H.; Nakamura, M. Inflammatory cascades mediate synapse elimination in spinal cord compression. J. Neuroinflamm. 2014, 11, 40. [CrossRef] [PubMed]

31. Beattie, M.S.; Manley, G.T. Tight squeeze, slow burn: Inflammation and the aetiology of cervical myelopathy. Brain 2011, 134, 1259-1261. [CrossRef] [PubMed]

32. Murphy, R.K.J.; Sun, P.; Xu, J.Q.; Wang, Y.; Sullivan, S.; Gamble, P.; Wagner, J.; Wright, N.N.; Dorward, I.G.; Riew, D.; et al. Magnetic Resonance Imaging Biomarker of Axon Loss Reflects Cervical Spondylotic Myelopathy Severity. Spine 2016, 41, 751-756. [CrossRef] [PubMed]

33. Allison, D.J.; Ditor, D.S. Immune dysfunction and chronic inflammation following spinal cord injury. Spinal Cord 2015, 53, 14-18. [CrossRef] [PubMed]

34. Steilen, D.; Hauser, R.; Woldin, B.; Sawyer, S. Chronic neck pain: Making the connection between capsular ligament laxity and cervical instability. Open Orthop. J. 2014, 8, 326-345. [PubMed]

35. Menezes, A.H. Craniovertebral junction database analysis: Incidence, classification, presentation, and treatment algorithms. Childs Nerv. Syst. 2008, 24, 1101-1108. [CrossRef] [PubMed]

36. Mitchell, J. Vertebral Artery Blood flow Velocity Changes Associated with Cervical Spine rotation: A Meta-Analysis of the Evidence with implications for Professional Practice. J. Man. Manip. Ther. 2009, 17, 46-57. [CrossRef] [PubMed]

37. Watson, D.H.; Drummond, P.D. Head pain referral during examination of the neck in migraine and tension-type headache. Headache 2012, 52, 1226-1235. [CrossRef] [PubMed]

38. Fernandez-de-Las-Penas, C.; Cuadrado, M.L.; Pareja, J.A. Myofascial trigger points, neck mobility and forward head posture in unilateral migraine. Cephalalgia 2006, 26, 1061-1070. [CrossRef] [PubMed]

39. Fernandez-de-Las-Penas, C. Myofascial Head Pain. Curr. Pain Headache Rep. 2015, 19, 28. [CrossRef] [PubMed]

40. Noseda, R.; Constandil, L.; Bourgeais, L.; Chalus, M.; Villanueva, L. Changes of meningeal excitability mediated by corticotrigeminal networks: A link for the endogenous modulation of migraine pain. J. Neurosci. 2010, 30, 14420-14429. [CrossRef] [PubMed]

41. Sauro, K.M.; Becker, W.J. The stress and migraine interaction. Headache 2009, 49, 1378-1386. [CrossRef] [PubMed]

42. Revanappa, K.K.; Moorthy, R.K.; Alexander, M.; Rajshekhar, V. Recovery of sympathetic skin response after central corpectomy in patients with moderate and severe cervical spondylotic myelopathy. Br. J. Neurosurg. 2017, 31, 199-204. [CrossRef] [PubMed]

43. Li, J.; Gu, T.; Yang, H.; Liang, L.; Jiang, D.J.; Wang, Z.C.; Yuan, W.; Wang, X.W. Sympathetic nerve innervation in cervical posterior longitudinal ligament as a potential causative factor in cervical spondylosis with sympathetic symptoms and preliminary evidence. Med. Hypotheses 2014, 82, 631-635. [CrossRef] [PubMed]

44. Gu, Q.G.; Jiang, D.J.; Wang, X.W.; Chen, D.Y.; Yuan, W. Chronic compression of the posterior longitudinal ligament of the cervical spine is associated with abnormal discharge of middle cervical ganglion. Int. J. Clin. Exp. Med. 2014, 7, 4316-4321. [PubMed]

45. Peng, K.P.; Wang, S.J. Migraine diagnosis: Screening items, instruments, and scales. Acta Anaesthesiol. Taiwan 2012, 50, 69-73. [CrossRef] [PubMed]

(C) 2018 by the authors. Licensee MDPI, Basel, Switzerland. This article is an open access article distributed under the terms and conditions of the Creative Commons Attribution (CC BY) license (http://creativecommons.org/licenses/by/4.0/). 